\title{
Discrimination reversal following learning without "errors"'
}

Pigeons were trained on a discrimination using the "errorless" procedure devised by Terrace and then given a discrimination reversal. Their extinction to the previously positive cue during reversal was similar to a control group given continuous reinforcement during original training. Most of the Ss in the errorless group, however, failed to learn the reversal because they did not respond to the previously. negative cue during five days of reversal training.

The purpose of the present experiment was to investigate discrimination reversal following training with the "errorless" procedure devised by Terrace (1963). There are several possible sources of interference during discrimination reversal following the usual training in which nonrewarded responses have been made to S-. The interspersed nonrewarded responses may produce an effect similar to that produced by partial reinforcement and thus increase the resistance to extinction of responses to the originally positive cue during reversal. Jenkins (1961) and D'Amato, Schiff, \& Jagoda (1962) have reported such increased resistance to extinction of responses to the positive cue following discrimination learning with errors. In the usual discrimination learning with errors, acquisition to the previously negative cue during reversal may be retarded because the nonrewarded responses during original learning may produce inhibition (Spence, 1936) or frustration (Amsel, 1962).

In the errorless procedure neither of these sources of interference would presumably be present during reversal. Reinforcement is continuous with regard to responses during original learning, and Terrace (1964, 1966) has argued that no inhibition to S- develops during errorless acquisition.

In the present experiment, the reversal performance of a group given errorless training was compared with the performance of a control group given continuous reinforcements to $\mathrm{S}+$ during training and given no training to the negative cue.

\section{Subjects}

The Ss were 10 experimentally naive Silver King pigeons maintained at $75-80 \%$ of their ad lib body weights during the experiment.

\section{Apparatus}

A double key Skinner box for pigeons similar to that described by Honig (1962) was used. One of the keys was inoperative and masked in the Ss' chamber. The stimuli were red and green Wratten filters mounted in an in-line display unit similar to that used by Terrace (1963). The timing of the trials, reinforcements, etc. was controlled by programming equipment housed in a separate room adjacent to the Ss' chamber.

\section{Procedure}

Five Ss each were assigned to the experimental and control groups. A successive discrete response terminated trial procedure similar to that described by Terrace (1963, Experiment 2) was used. The experimental group was presented with the S- during the first session according to the "early progressive" procedure described by Terrace. Introduction of Sfollowed the shaping of the response to $S+$ which involved approximately 20 reinforcements. The duration of Swas gradually increased from $0.5 \mathrm{sec}$ to $5 \mathrm{sec}$, and the intensity of S- was increased by gradually reducing the resistance of a variable resistor in series with the lamp illuminating $\mathrm{S}-$ from $80 \mathrm{ohms}$ to 0 ohms.

In all sessions except the first the duration and intensity of $\mathrm{S}-$ were at maximum value. For the experimental group, each daily session consisted of 132 trials in which S+ and S- were randomly alternated. The control group received the same mean number of reinforced responses to $S+$ as the Ss in the experimental group each day but were not given the S- trials. Following five days of training both groups were given a discrimination reversal problem for five daily sessions.

\section{Resulis}

Training. The mean number of responses to $\mathrm{S}-$ in the experimental group was minimal, ranging from 2.6 errors on Day 1 to 1.4 errors on Day 5 of training.

Reversal. The extinction to the previously positive cue and the acquisition to the previously negative cue is shown in Fig. 1. The rate of extinction to the previously positive cue is very similar in the experimental and control groups, and they do not differ significantly in the number of responses given to the previously positive cue during reversal $(t=0.67$, $\mathrm{df}=8, \mathrm{p}>.25$ ).

Four out of the five $S s$ in the experimental group did not respond to $S+$ more than once during the five days of reversal training involving a total of 330 $\mathrm{S}+$ trials. One experimental $\mathrm{S}$ did respond to $\mathrm{S}+$ during reversal but did not reach $90 \%$ correct in the five days of reversal training. The Ss in the control group responded to $S+$ throughout the five days of 


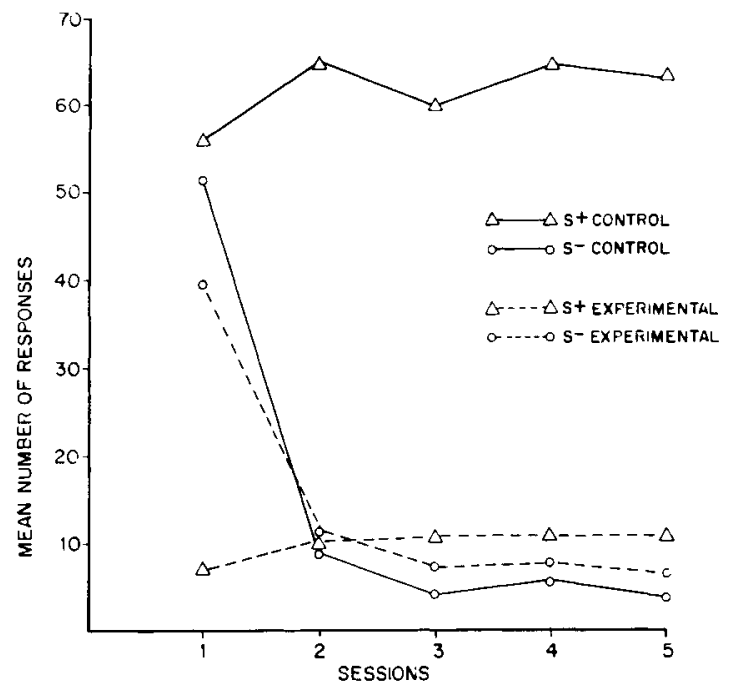

Fig. 1. The mean number of responses to $S^{+}$and $S-$ in the experimental and control groups during reversal training.

reversal and reached $96 \%$ correct by Day 5 (Fig. 2). The experimental and control groups differ significantly in the number of responses given to the new $S+$ during reversal (Mann Whitney $U=0, p<.008$, two tailed).

\section{Discussion}

The results of the present experiment indicate that

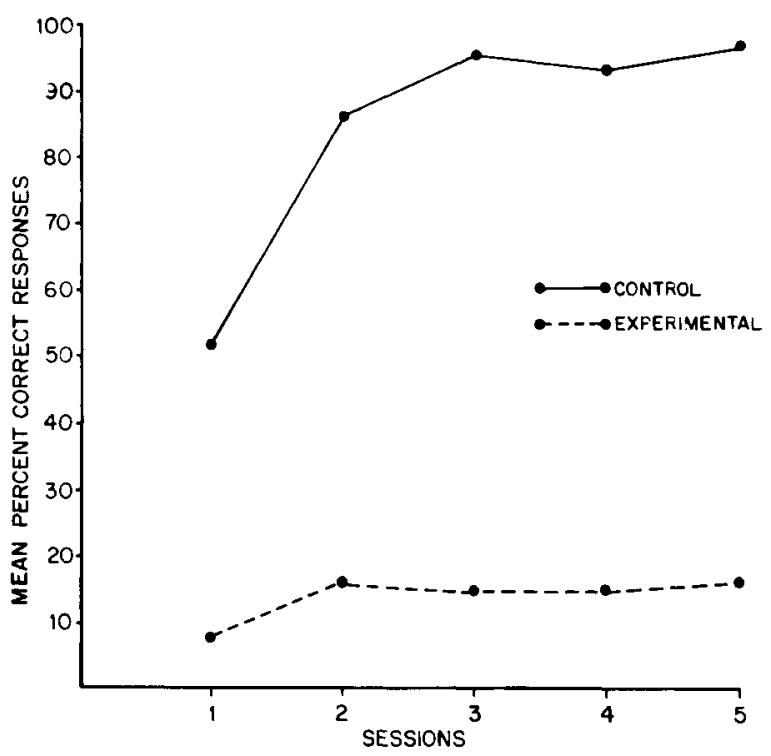

Fig. 2. The mean percentage correct in the experimental and control groups during reversal training. the extinction curve to the positive cue following errorless training resembles that obtained following continuous reinforcement rather than intermittent reinforcement. The present results are therefore in contrast to the results obtained in the usual discrimination experiment involving nonrewarded responses (Jenkins, 1961; D'Amato, Schiff, \& Jagoda, 1962).

On the other hand most of the Ss in the experimental group failed to respond to the previously negative cue during reversal even though they made very few nonrewarded responses to it during original learning. This is unexpected because Terrace has argued that no inhibition to the negative cue develops during errorless training. Terrace based this argument on the absence of a peak shift in the generalization gradient (1964) and the failure to find a generalization gradient of inhibition around the $\mathrm{S}-$ following errorless training (1966).

The criteria for determining when a stimulus has inhibitory control are not well defined (cf. Jenkins, 1965). In the Terrace (1966) experiment the Ss in the errorless group actually made fewer responses to the stimuli along the S- dimension than those in the error group. It is evident that the negative stimulus following errorless training has good control over not responding. Whether or not one can attribute this control to "inhibition" is not clear.

\section{References}

AMSEL, A. Frustative nonreward in partial reinforcement and discrimination learning. Some recent history and a theoretical extension. Psychol. Rev., 1962, 69, 306-328.

D'AMATO, M. R., SCHIFF, D., \& JAGODA, H. Resistance to extinction after varying amounts of discriminative or non-discriminative instrumental training. J. exp. Psychol, 1962, 64, 526-532.

HONIG, W. K. Prediction of preference, transposition and transpositionreversal from the generalization gradient. J. exp. Psychol., 1962, 64, 239-248.

JENKINS, H. M. Generalization gradients and the concept of inhibition. In D. Mostofsky (Ed.), Stimulus Generalization. Stanford: Stanford University Press, 1965, pp. 55-61.

JENKINS, H. M. The effect of discrimination training on extinction. J. exp. Psychol, 1961, 61, 111-121.

SPENCE, K. W. The nature of discrimination learning in animals. Psychol. Rev, 1936, 43, 427.449.

TERRACE, H. S. Discrimination learning with and without "Errors." J. exp. Anal. Beh., 1963, 6, 1-27.

TERRACE, H. S. Wavelength generalization after discrimination learning with and without errors. Science, 1964, 144, 78-80.

TERRACE, H. S. Discrimination learning and inhibition. Science, 1966, $154,1677-1680$.

\section{Note}

1. This research was supported in part by Grant No. MH18104-01 from the National Institute of Mental Health to the first author. 